\title{
Hydrocarboxylation of Unactivated Internal Alkynes with Carboxylic Acids Catalyzed by Dinuclear Palladium Complexes
}

\author{
Naofumi Tsukada, ${ }^{* \dagger}$ Atsushi Takahashi, Yoshio Inoue \\ Graduate School of Engineering, Tohoku University, Sendai 980-8579, Japan
}

\begin{abstract}
Dinuclear palladium complexes catalyzed addition reactions of carboxylic acid $\mathrm{O}-\mathrm{H}$ bond to unactivated internal alkynes. The reaction afforded a trans-adduct selectively.
\end{abstract}

Keywords: palladium, catalysis, carboxylic acid, alkyne

Dinuclear transition metal complexes have been expected to have novel and unique functions as catalysts in organic synthesis. ${ }^{1}$ The cooperation of two metal centers could enable various transformations that are not possible using mononuclear metal complexes. We have previously reported that dinuclear palladium complexes with a novel bridging ligand, $N, N^{\prime}$-bis[2-(diphenylphosphino)phenyl] amidinate ${ }^{2}$ (dpfam), served as catalysts for selective addition reactions of various $\mathrm{sp}^{2}$ and $\mathrm{sp} \mathrm{C}-\mathrm{H}$ bonds to unactivated alkynes, ${ }^{3}$ which were not possible using mononuclear palladium complexes (Eq. 1). In the course of our study for the catalysis using $\mathbf{1}$, we found that the addition of carboxylic acid $\mathrm{O}-\mathrm{H}$ bond to unactivated internal alkynes proceeded in the presence of 1a (Eq. 2). Hydrocarboxylation of alkynes with carboxylic acids is an atom economical way to synthesize vinyl and alkenyl esters, some of which are industrially important compounds. ${ }^{4}$ Although there have been many reports concerning hydrocarboxylation catalyzed by transition metals, ${ }^{4,5}$ intermolecular addition to internal alkynes has been rather limited. ${ }^{6}$ Hidai et al. reported that a cuboidal palladium-molybdenum cluster served as a catalyst for addition to electron-deficient internal alkynes as well as terminal alkynes. ${ }^{6 a}$ Unactivated internal alkynes react with several carboxylic acids in the presence of silver salts. ${ }^{6 \mathrm{~b}} \mathrm{Ru}_{3}(\mathrm{CO})_{12}$ is also effective for the hydrocarboxylation of unactivated alkynes to afford $(Z)$-alkenyl esters. ${ }^{6 c-e}$

(compound 1 and 2, Eq. 1 and 2) 
Initially, the reaction of 3-hexyne with benzoic acid was carried out under reaction conditions similar to that for the hydroarylation ${ }^{3 \mathrm{a}}$ of internal alkynes using 1 (Eq. 3 and Table 1). Reactions in the presence of 1 and tri- $n$-butylborane at $100{ }^{\circ} \mathrm{C}$ afforded $Z-1$ ethylbut-1-enyl benzoate $\mathbf{3}^{7}$ as the sole product. No regio- and stereoisomers were observed. Hydroxo-bridged complexes $\mathbf{1 a}$ and $\mathbf{1 b}$ were more effective than halidebridged complexes 1c-e. Reaction using $\mathbf{1 a}$ or $\mathbf{1 b}$ as a catalyst afforded $\mathbf{3}$ in good yields (entries 1 and 2). Although 1c-e were wholly ineffective in the previous hydroarylation, ${ }^{3 a}$ hydrocarboxylation proceeded in the presence of $\mathbf{1 c}-\mathbf{e}$ to give $\mathbf{3}$ in moderate yields (entries 3-5). The addition of tri- $n$-butylborane is not essential for hydrocarboxylation in contrast to hydroarylation; however, the absence of the additive decreased the yield of $\mathbf{3}$ (entry 6). The addition of tri-sec-butylborane or lithium tri-tertbutoxyaluminum hydride did not affect the yield of $\mathbf{3}$ (entries 7 and 8). Next, several mononuclear complexes were employed as catalysts. The reaction did not proceed in the presence of ordinary palladium catalysts such as $\mathrm{Pd}\left(\mathrm{PPh}_{3}\right)_{4}$ and $\mathrm{Pd}(\mathrm{OAc})_{2}$ (entries 10 and 11). Only the mononuclear complex $\mathbf{2}$, which has the same ligand as the dinuclear complexes 1 have, showed very low catalytic activity (entry 9).

\section{(Eq. 3 and Table 1)}

Table 2 summarizes the results of the reaction of 3-hexyne with various carboxylic acids (Eq. 4). Most reactions with substituted benzoic acids also gave the corresponding alkenyl esters 4-12 (entries 1-9). While electron-donating groups slightly decrease the yield of the products, electron-withdrawing groups increase the yield (entries 1-4). An acetyl group at the ortho position inhibits the reaction, probably due to deactivation of the catalyst by chelation (entry 5). In several cases, small amounts of isomers were observed by GC-MS. The structure of the isomers was determined by ${ }^{1} \mathrm{H}$ NMR spectra only in two reactions where significant amounts of isomers were formed (entries 2 and 8 ). The standard reaction conditions are unsuitable for the reaction with $p$-toluic acids (entry 9). In this case, the reaction mixture was heterogeneous because only a small amount of THF was used as the solvent and $p$-toluic acid has lower solubility and a higher melting point. Although nitrogenous heteroaromatic carboxylic acids such as 2picolinic acid and pyrrole-2-carboxylic acid inhibited the addition (entries 10 and 11), the reaction of 2-furoic acid or 2-thiophenecarboxylic acid gave the corresponding adducts 15 and 16, respectively (entries 12 and 13). Alkenoic acids can also be used for hydrocarboxylation (entries 14-16); the reaction of cinnamic acid afforded the adduct 
17 in a satisfactory yield. Most aliphatic carboxylic acids exhibited low reactivity. Among them, phenyl-substituted acids, such as phenylacetic acid and hydrocinnamic acid were more reactive, and adducts $\mathbf{2 4}$ and $\mathbf{2 5}$ were obtained from their reactions (entries 21 and 22).

(Eq. 4 and Table 2)

Table 3 summarizes the results of the reaction of various alkynes with benzoic acid (Eq. 5). Various dialkylethynes reacted with benzoic acid as well as 3-hexyne to provide the corresponding esters 26-29 (entries 1-4). Unfortunately, a hindered group inhibited the reaction (entry 3 ) and the regioselectivity in the reaction of 2-octyne was low (entry 4). The regioselectivity increased slightly in the reactions of phenyl-substituted alkynes (entries 6 and 7), and was significantly improved in the reaction of methyl butynoate, although the $E / Z$ ratio was low (entry 9). Terminal alkynes such as phenylacetylene and 1-hexyne afforded no adducts.

\section{(Eq. 5 and Table 3)}

While hydroarylation did not proceed without trialkylboranes, ${ }^{3 a}$ those are not essential for hydrocarboxylation. As indicated previously, trialkylboranes could serve as a hydride source to transform a hydroxo-bridged complex to a hydride-bridged complex, which could be a true reaction intermediate. ${ }^{3 a}$ Actually, lithium tri-tert-butoxyaluminum hydride can be used instead of trialkylboranes. ${ }^{3 b}$ An acidic hydrogen atom of benzoic acid would be a hydride source for generation of a hydride-bridged complex. ${ }^{8}$ Therefore hydrocarboxylation does not need additives essentially.

Hydroarylation, $^{3 a, b}$ hydroalkenylation ${ }^{3 \mathrm{c}}$ and hydroalkynylation ${ }^{3 \mathrm{~d}}$ catalyzed by $\mathbf{1}$ proceeded selectively via $c i s$-addition, whereas the present hydrocarboxylation afforded mainly trans-adducts. To elucidate whether the trans-adducts were generated by the isomerization of $c i s$-adducts, the $E / Z$ ratio of products was observed at the early stage of several reactions. After $1 \mathrm{~h}$, the reaction of 3-hexyne with benzoic acid gave only the trans-adduct Z-3 in low yield and with high stereoselectivity (Eq. 6). The $E / Z$ ratio of 34 in the 1-h reaction of methyl butynoate was 29/71, which was similar to that after 17 h (Table 3, entry9). Next, the pure $E$-isomer of $\mathbf{3}$, which was prepared by a different method, ${ }^{6 \mathrm{~d}}$ was added to the reaction of 4-octyne with benzoic acid (Eq. 7). After $17 \mathrm{~h}$, no isomerization of E-3 to Z-3 was observed. These results show that the trans-adducts are not generated by isomerization of the cis-adducts. 
(Eq. 6 and 7)

Although there is little evidence for the mechanistic aspects at the present time, one of possible mechanisms for the reaction of 3-hexyne with benzoic acid are described in Scheme $1 .{ }^{3 e}$ As mentioned above, the reaction of $\mathbf{1 a}$ with tri- $n$-butylborane could give hydride-bridged complex $\mathbf{3 5}$. Reductive elimination of toluene from $\mathbf{3 5}$, followed by protonation of another tolyl ligand with benzoic acid, would afford benzoate complex 36. Insertion of 3-hexyne into $\mathrm{Pd}-\mathrm{Pd}$ bond $^{9}$ of $\mathbf{3 6}$ and reductive elimination on the right palladium center could result in cis-addition to give alkenyl palladium complex 37 (path A). Complex 38 could be generated via $E / Z$ isomerization of the alkenyl ligand, ${ }^{10}$ and protonated with benzoic acid to afford $Z-3$. Nucleophilic attack of benzoate to alkyne from the opposite side of palladium in $\mathbf{3 6}$ could also complex $\mathbf{3 8}$ directly (path B).

(Scheme 1)

In summary, the dinuclear palladium complex 1 catalyzed the hydrocarboxylation of internal alkynes with carboxylic acids to predominantly yield trans-adducts. The precise reaction mechanism and addition reactions of other $\mathrm{O}-\mathrm{H}$ bonds to alkynes are under investigation.

\section{Supplementary data}

Supplementary data (experimental details and product characterizations) associated with this article can be found, in the online version, at doi:

\section{References and notes}

$\dagger \quad$ Present address: Department of Chemistry, Faculty of Science, Shizuoka University, Shizuoka 422-8529, Japan. Tel/Fax: +81 54238 4759, e-mail: sntsuka@ipc.shizuoka.ac.jp.

1 (a) Bullock, R. M.; Casey, C. P. Acc. Chem. Res. 1987, 20, 167.

(b) Steimhagen, H.; Helmchen, G. Angew. Chem. Int. Ed. Engl. 1996, 35, 2339.

(c) van den Beuken, E. K.; Feringa, B. L. Tetrahedron 1998, 54, 12985.

(d) Rowlands, G. J. Tetrahedron 2001, 57, 1865.

(e) Multimetallic Catalysis in Organic Synthesis; Shibasaki, M.; Yamamoto, Y., Eds.; Wiley-VCH: Weinheim, 2004.

2 Tsukada, N.; Tamura, O.; Inoue, Y. Organometallics 2002, 21, 2521. 
(a) Tsukada, N.; Mitsuboshi, T.; Setoguchi, H.; Inoue, Y. J. Am. Chem. Soc. 2003, 125, 12102 .

(b) Tsukada, N.; Murata, K.; Inoue, Y. Tetrahedron Lett. 2005, 46, 7515.

(c) Tsukada, N.; Setoguchi, H.; Mitsuboshi, T.; Inoue, Y. Chem. Lett. 2006, 35, 1164.

(d) Tsukada, N.; Ninomiya, S.; Aoyama, Y.; Inoue, Y. Org. Lett. 2007, 9, 2919.

(e) Tsukada, N.; Ninomiya, S.; Aoyama, Y.; Inoue, Y. Pure Appl. Chem. 2008, 80,1161 .

4 Catalytic Heterofunctionalization; Togni, A., Grützmacher, H., Eds.; WilleyVCH: Weinheim, 2001.

5 (a) Larock, R. C.; Leong, W. W. In Comprehensive Organic Synthesis; Trost, B, M.; Fleming, I., Eds.; Pergamon Press: Oxford, 1991; Vol. 4, p 269.

(b) Yamamoto, Y.; Radhakrishnan, U. Chem. Soc. Rev. 1999, 28, 199.

(c) Alonso, F.; Beletskaya, I. P.; Yus, M. Chem. Rev. 2004, 104, 3079.

(a) Wakabayashi, T.; Ishii, Y.; Murata, T.; Mizobe, Y.; Hidai, M. Tetrahedron Lett. 1995, 36, 5585.

(b) Ishino, Y.; Nishiguchi, I.; Nakao, S.; Hirashima, T. Chem. Lett. 1981, 641.

(c) Ruppin, C.; Dixneuf, P. H. Tetrahedron Lett. 1986, 27, 6323.

(d) Rotem, M.; Shvo, Y. J. Organomet. Chem. 1993, 448, 189.

(e) Menashe, N.; Shvo, Y.J. Org. Chem. 1993, 58, 7434.

7 The stereochemistry of $\mathbf{3}$ was determined by NOE experiments and comparison of ${ }^{1} \mathrm{H}$ NMR chemical shifts of $\mathbf{3}$ with those of similar alkenyl esters.

8 Grushin, V. V. Chem. Rev. 1996, 96, 2011.

9 Puddephatt, R. J. Chem. Soc. Rev. 1983, 12, 99.

10 (a) Brady, K. A.; Niles, T. A. J. Organomet. Chem. 1981, 206, 299.

(b) de Vaal, P.; Dedieu, A. J. Organomet. Chem. 1994, 478, 121.

(c) Amatore, C.; Bensalem, S.; Ghalem, S.; Jutand, A. J. Organomet. Chem. 2004, 689, 4642.

(d) Chung, L. W.; Wu, Y.-D.; Trost, B. M.; Ball, Z. T. J. Am. Chem. Soc. 2003, 125, 11578 . 
Table 1. Pd-catalyzed addition of benzoic acid to 3-hexyne

\begin{tabular}{llll}
\hline run & catalyst $(\mathrm{mol} \%)$ & additive & yield $^{\mathrm{b}}(\%)$ \\
\hline 1 & $\mathbf{1 a}(2)$ & $\mathrm{B}(n-\mathrm{Bu})_{3}$ & 71 \\
2 & $\mathbf{1 b}(2)$ & $\mathrm{B}(n-\mathrm{Bu})_{3}$ & 65 \\
3 & $\mathbf{1 c}(2)$ & $\mathrm{B}(n-\mathrm{Bu})_{3}$ & 27 \\
4 & $\mathbf{1 d}(2)$ & $\mathrm{B}(n-\mathrm{Bu})_{3}$ & 44 \\
5 & $\mathbf{1 e}(2)$ & $\mathrm{B}(n-\mathrm{Bu})_{3}$ & 41 \\
6 & $\mathbf{1 a}(2)$ & none & 53 \\
7 & $\mathbf{1 a}(2)$ & $\mathrm{B}(\text { sec-Bu })_{3}$ & 55 \\
8 & $\mathbf{1 a}(2)$ & $\mathrm{LiAl}(\mathrm{O}-t-\mathrm{Bu})_{3} \mathrm{H}$ & 51 \\
9 & $\mathbf{2}(4)$ & $\mathrm{B}(n-\mathrm{Bu})_{3}$ & 4 \\
10 & $\mathrm{Pd}(\mathrm{PPh})_{4}(4)$ & $\mathrm{B}(n-\mathrm{Bu})_{3}$ & 0 \\
11 & $\mathrm{Pd}(\mathrm{OAc})_{2}(4)$ & $\mathrm{B}(n-\mathrm{Bu})_{3}$ & 0 \\
12 & none & $\mathrm{B}(n-\mathrm{Bu})_{3}$ & 0
\end{tabular}

${ }^{\mathrm{a}} \mathrm{A}$ mixture of 3-hexyne $(0.5 \mathrm{mmol})$ and benzoic acid $(5.0 \mathrm{mmol})$ was stirred at $100{ }^{\circ} \mathrm{C}$ for $17 \mathrm{~h}$ in the presence of a palladium complex $(0.01-0.02 \mathrm{mmol})$ and an additive $(0.15$ mmol). ${ }^{b}$ Determined by GC. 
Table 2. Pd-catalyzed addition of various carboxylic acids to 3-hexyne

\begin{tabular}{llll}
\hline run & $\mathrm{R}^{1}$ & product & yield $^{\mathrm{b}}(\%)$ \\
\hline 1 & $o-\mathrm{MeC}_{6} \mathrm{H}_{4}$ & $\mathbf{4}$ & 58 \\
2 & $o-\mathrm{MeOC}_{6} \mathrm{H}_{4}$ & $\mathbf{5}$ & $40^{\mathrm{c}}$ \\
3 & $o-\mathrm{CF}_{3} \mathrm{C}_{6} \mathrm{H}_{4}$ & $\mathbf{6}$ & 88 \\
4 & $o-\mathrm{FC}_{6} \mathrm{H}_{4}$ & $\mathbf{7}$ & 62 \\
5 & $o-\mathrm{CH}_{3}(\mathrm{C}=\mathrm{O}) \mathrm{C}_{6} \mathrm{H}_{4}$ & $\mathbf{8}$ & trace \\
6 & $m-\mathrm{MeC}_{6} \mathrm{H}_{4}$ & $\mathbf{9}$ & 24 \\
7 & $m-\mathrm{MeOC}_{6} \mathrm{H}_{4}$ & $\mathbf{1 0}$ & 41 \\
8 & $m-\mathrm{CF}_{3} \mathrm{C}_{6} \mathrm{H}_{4}$ & $\mathbf{1 1}$ & $32^{\mathrm{d}}$ \\
9 & $p-\mathrm{CH}_{3} \mathrm{C}_{6} \mathrm{H}_{4}$ & $\mathbf{1 2}$ & trace \\
10 & $2-$ pyrroryl & $\mathbf{1 3}$ & 0 \\
11 & $2-$ pyridyl & $\mathbf{1 4}$ & 0 \\
12 & $2-$ furyl & $\mathbf{1 5}$ & 57 \\
13 & $2-$ thienyl & $\mathbf{1 6}$ & 50 \\
14 & trans $-\mathrm{PhCH}=\mathrm{CH}$ & $\mathbf{1 7}$ & 74 \\
15 & trans $-\mathrm{PrCH}=\mathrm{CH}$ & $\mathbf{1 8}$ & 42 \\
16 & trans $-\mathrm{MeCH}=\mathrm{CH}$ & $\mathbf{1 9}$ & 29 \\
17 & Me & $\mathbf{2 0}$ & 20 \\
18 & Et & $\mathbf{2 1}$ & 23 \\
19 & ClCH & $\mathbf{2 2}$ & 23 \\
20 & cyclohexyl & $\mathbf{2 3}$ & 42 \\
21 & PhCH & $\mathbf{2 4}$ & 47 \\
22 & PhCH ${ }_{2} \mathrm{CH}$ & $\mathbf{2 5}$ & 66 \\
\hline
\end{tabular}

${ }^{a}$ A mixture of 3-hexyne (0.5 mmol) and a carboxylic acid $(5.0 \mathrm{mmol})$ was stirred at $100{ }^{\circ} \mathrm{C}$ for $17 \mathrm{~h}$ in the presence of $\mathbf{1 a}(0.01 \mathrm{mmol})$ and $\mathrm{B}(n-\mathrm{Bu})_{3}(0.15 \mathrm{mmol}, 1 \mathrm{M}$ THF solution). ${ }^{\mathrm{b}}$ Isolated yields. ${ }^{\mathrm{c}} E / Z=14 / 86 .{ }^{\mathrm{d}} E / Z=24 / 76$. 
Table 3. Pd-catalyzed addition of benzoic acid to various alkynes ${ }^{\mathrm{a}}$

\begin{tabular}{|c|c|c|c|c|c|}
\hline entry & $\mathrm{R}^{2}$ & $\mathrm{R}^{3}$ & product & yield $^{\mathrm{b}}(\%)$ & $\mathbf{a}: \mathbf{b}$ \\
\hline 1 & $n$-Pr & $n$-Pr & 26 & 29 & - \\
\hline 2 & $n-\mathrm{Bu}$ & $n-\mathrm{Bu}$ & 27 & 32 & - \\
\hline 3 & $\mathrm{Me}$ & $t-\mathrm{Bu}$ & 28 & 0 & - \\
\hline 4 & $\mathrm{Me}$ & $n-\mathrm{C}_{5} \mathrm{H}_{11}$ & 29 & 58 & $51: 49$ \\
\hline 5 & $\mathrm{Ph}$ & $\mathrm{Ph}$ & 30 & 15 & - \\
\hline 6 & $\mathrm{Me}$ & $\mathrm{Ph}$ & 31 & 55 & $65: 35$ \\
\hline 7 & $\mathrm{Et}$ & $\mathrm{Ph}$ & 32 & $36^{\mathrm{c}}$ & $69: 31$ \\
\hline 8 & $\mathrm{CO}_{2} \mathrm{Me}$ & $\mathrm{CO}_{2} \mathrm{Me}$ & 33 & $41^{\mathrm{d}}$ & - \\
\hline 9 & $\mathrm{Me}$ & $\mathrm{CO}_{2} \mathrm{Me}$ & 34 & $70^{\mathrm{e}}$ & 100:0 \\
\hline
\end{tabular}




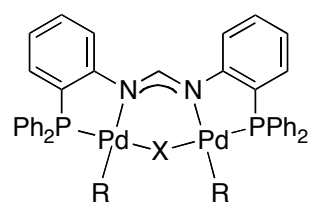

1a $(\mathrm{X}=\mathrm{OH}, \mathrm{R}=p$-Tol)

$1 b(X=O H, R=M e)$

1c $(\mathrm{X}=\mathrm{I}, \mathrm{R}=p$-Tol)

1d $(\mathrm{X}=\mathrm{Br}, \mathrm{R}=p$-Tol $)$
1e $(\mathrm{X}=\mathrm{Cl}, \mathrm{R}=p$-Tol $)$

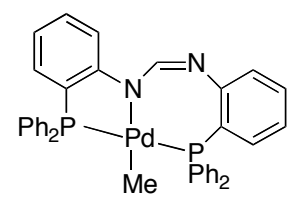

2

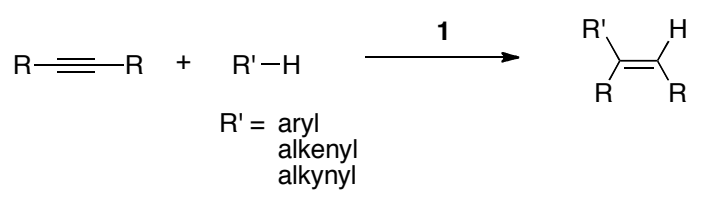

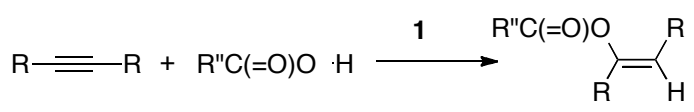




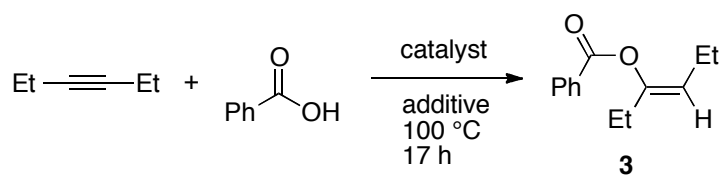

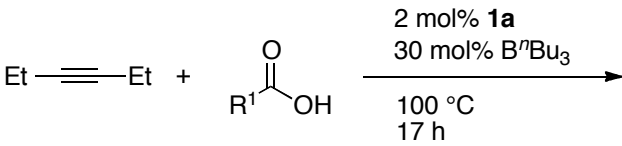

$$
\begin{aligned}
& \left.\mathrm{Et}_{\mathrm{Et}}^{\mathrm{O}}\right\rangle_{\mathrm{H}}^{\mathrm{Ot}} \\
& \text { 4-25 }
\end{aligned}
$$

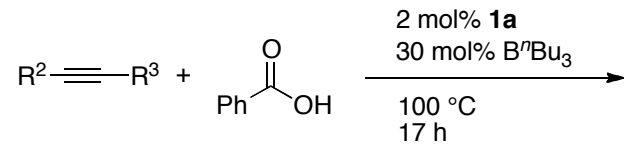

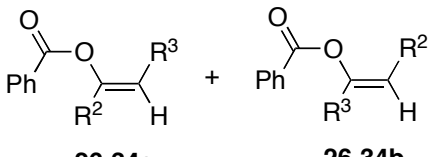

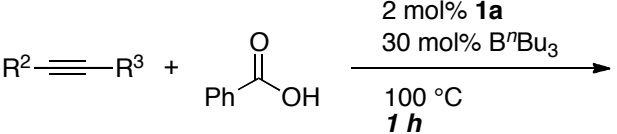

$$
\begin{aligned}
& \stackrel{\mathrm{O}}{\mathrm{O}} \underset{\mathrm{R}}{\mathrm{O}=\mathrm{R}^{5}} \mathrm{R}_{\mathrm{H}}^{3}
\end{aligned}
$$

$3\left(R^{2}=R^{3}=E t\right) ; 21 \%(E / Z=<1 />99)$

34a $\left(R^{2}=\mathrm{Me}, \mathrm{R}^{3}=\mathrm{CO}_{2} \mathrm{Me}\right) ; 37 \%(\mathrm{E} / \mathrm{Z}=28 / 72)$
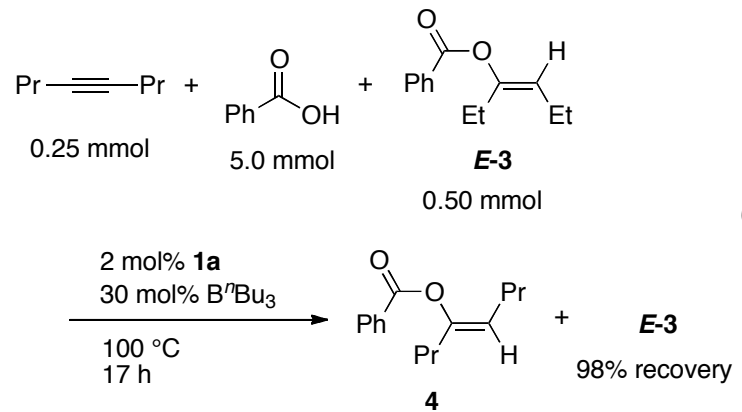


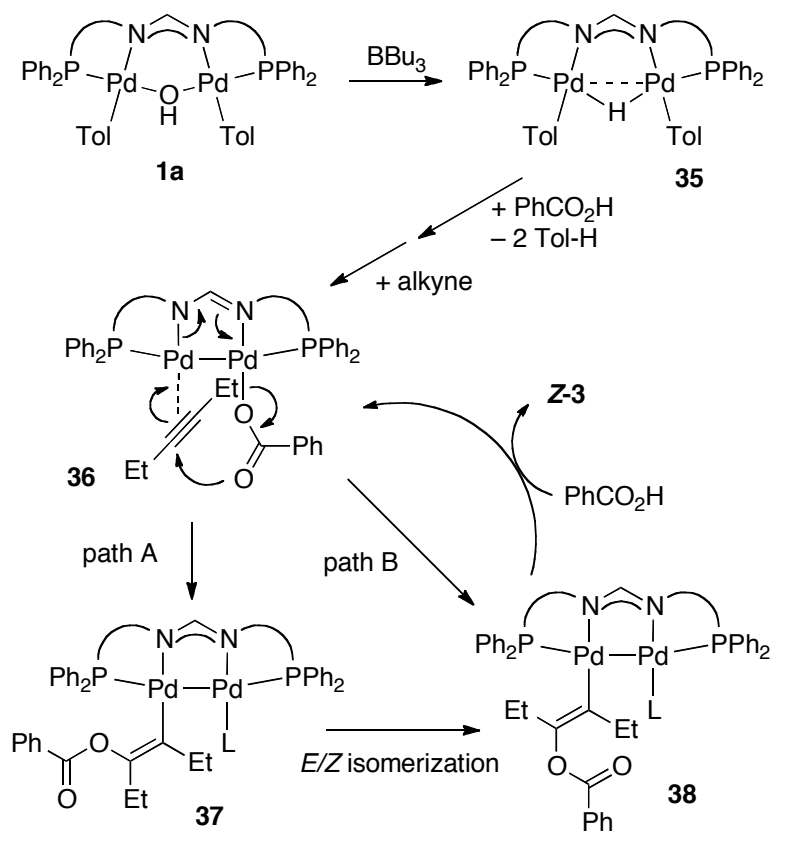

Scheme 1 Possible Mechanisms 